\title{
Long-term regulation of pyruvate dehydrogenase complex
}

\section{Evidence that kinase-activator protein (KAP) is free pyruvate dehydrogenase kinase}

\author{
Bethan S. JONES and Stephen J. YEAMAN* \\ Department of Biochemistry and Genetics, Medical School, University of Newcastle upon Tyne, Newcastle upon Tyne NE2 4HH, \\ U.K.
}

\begin{abstract}
The kinase-activator protein (KAP) of pyruvate dehydrogenase complex (PDC) has been purified approx. 2250-fold from high-speed supernatants of mitochondrial extracts from the liver of $48 \mathrm{~h}$-starved rats. Purified KAP demonstrates kinase activity towards both the E1 component of PDC and towards a synthetic peptide corresponding to the major phosphorylation site on E1. Furthermore, the activities of KAP and PDC kinase co-fractionate through several stages of purification and have the same apparent mass. We conclude that KAP is not a distinct protein, but is kinase which has dissociated from the complex.
\end{abstract}

\section{INTRODUCTION}

Pyruvate dehydrogenase complex (PDC) occupies a key position in intermediary metabolism, and its activity is under stringent acute and long-term control [1]. Two major mechanisms are employed, namely end-product inhibition by NADH and acetyl-CoA [2,3] and also reversible phosphorylation [4]. Phosphorylation of the $\alpha$-subunit of the pyruvate dehydrogenase component (E1) by a specific kinase endogenous to the complex causes complete loss of activity, which is regained only by dephosphorylation by a loosely bound protein phosphatase [5-7].

Starvation or diabetes causes decreased activity of PDC in several tissues (e.g. liver, muscle, heart) [8], which results from a stable increase in PDC kinase activity $[9,10]$. This has been attributed to two events: increased levels of PDC kinase associated with the complex, and also synthesis of a distinct kinaseactivator protein (KAP), which is apparently capable of activating the kinase endogenous to the complex $[11,12]$.

In the present paper, we report extensive purification of KAP from rat liver mitochondria and, on the basis of its properties, conclude that it is not a distinct protein, but that it is identical with the PDC kinase itself.

\section{EXPERIMENTAL}

\section{Preparation of rat liver mitochondria}

Male (180 g) Wistar rats (fed, or fasted for $48 \mathrm{~h}$ ) were killed, and the livers were removed and rinsed immediately in ice-cold $0.25 \mathrm{M}$-sucrose/5 mM-Tris/HCl (pH 7.4)/2 mM-EGTA (buffer A). The tissue was then weighed, chopped and homogenized in 5 vol. of buffer A by using a Polytron with a $1 \mathrm{~cm}$ probe (setting 3,10 bursts of $3 \mathrm{~s}$ each). The homogenate was centrifuged at $500 \mathrm{~g}$ for $10 \mathrm{~min}$, the supernatant was retained and the pellets were resuspended in buffer $\mathrm{A}$, homogenized and re-centrifuged as above. Mitochondria were then prepared from the combined supernatants by centrifugation at $10000 \mathrm{~g}$ for $10 \mathrm{~min}$. The mitochondrial pellets were resuspended in buffer A, care being taken to remove the fluffy (lysosome-containing) layer, washed by re-centrifugation at $10000 \mathrm{~g}$ and resuspended in buffer $\mathrm{A}$ to a protein concentration of approx. $4 \mathrm{mg} / \mathrm{ml}$. All steps were carried out at $4^{\circ} \mathrm{C}$.

\section{Purification of PDC and its component enzymes}

Bovine PDC was purified essentially by the method in [13]. Homogeneous preparations of the E1 component, devoid of endogenous PDC kinase activity, were obtained by resolution of the complex by gel-filtration chromatography on Superose 6 at pH 9.0 in $1 \mathrm{M}-\mathrm{NaCl},\left(\mathrm{NH}_{4}\right)_{2} \mathrm{SO}_{4}$ precipitation (40\% satn.), followed by ion-exchange chromatography on Mono-Q (P. Dent, K. G. Cook \& S. J. Yeaman, unpublished work). Highly purified preparations of PDC kinase were obtained from the same Mono$\mathrm{Q}$ column and were further purified by gel-filtration chromatography on Superose 12.

\section{Purification of KAP}

The mitochondria were extracted by the addition of Triton $\mathrm{X}$ 100 to $3 \%(\mathrm{v} / \mathrm{v})$ and stirring for $30 \mathrm{~min}$ at $4{ }^{\circ} \mathrm{C}$. Insoluble material was removed by centrifugation at $10000 \mathrm{~g}$ for $10 \mathrm{~min}$. PDC was removed from the mitochondrial extract by ultracentrifugation at $150000 \mathrm{~g}$ for $2.5 \mathrm{~h}$ (or by gel-filtration chromatography on preparative-grade Superose 6). The PDC-free high-speed supernatant was then dialysed against $50 \mathrm{~mm}$ imidazole (pH 7.4)/1 mm-dithiothreitol/0.1 mM-EDTA/1 mMphenylmethanesulphonyl fluoride/1 mM-benzamidine (buffer B) and then subjected to ion-exchange chromatography on Whatman DE52 DEAE-cellulose ( $15 \mathrm{~cm} \times 2.5 \mathrm{~cm}$ column) equilibrated in buffer B containing $100 \mathrm{~mm}-\mathrm{NaCl}$. KAP was eluted in buffer B containing $250 \mathrm{mM}-\mathrm{NaCl}$, and fractions containing KAP were then combined and dialysed against buffer B containing $50 \%$ (v/v) glycerol.

Affinity chromatography was then carried out on Amicon Matrex Orange A $(10 \mathrm{~cm} \times 1 \mathrm{~cm}$ column) equilibrated in buffer B. After loading and washing, elution was carried out in buffer B containing $100 \mathrm{mM}-\mathrm{NaCl}$, and fractions containing KAP activity were pooled and dialysed against buffer $\mathbf{B}$ containing $50 \%$ glycerol. This material was then loaded on to a Dionex Propac column equilibrated in buffer B. The column was washed with $40 \mathrm{ml}$ of buffer $\mathrm{B}$ and eluted with a linear $\mathrm{NaCl}$ gradient $(0-0.5 \mathrm{M})$ in buffer B. KAP was eluted routinely at approx. $150 \mathrm{~mm}-\mathrm{NaCl}$. Fractions containing KAP activity were pooled, desalted and concentrated by using Amicon Microcentricon units and then loaded on to ATP-agarose (Sigma no. A6888).

\footnotetext{
Abbreviations used: PDC, pyruvate dehydrogenase complex; E1, pyruvate dehydrogenase component (EC 1.2.4.1) of PDC; KAP, kinase-activator protein; NEM, $N$-ethylmaleimide.

* To whom correspondence and reprint requests should be addressed.
} 


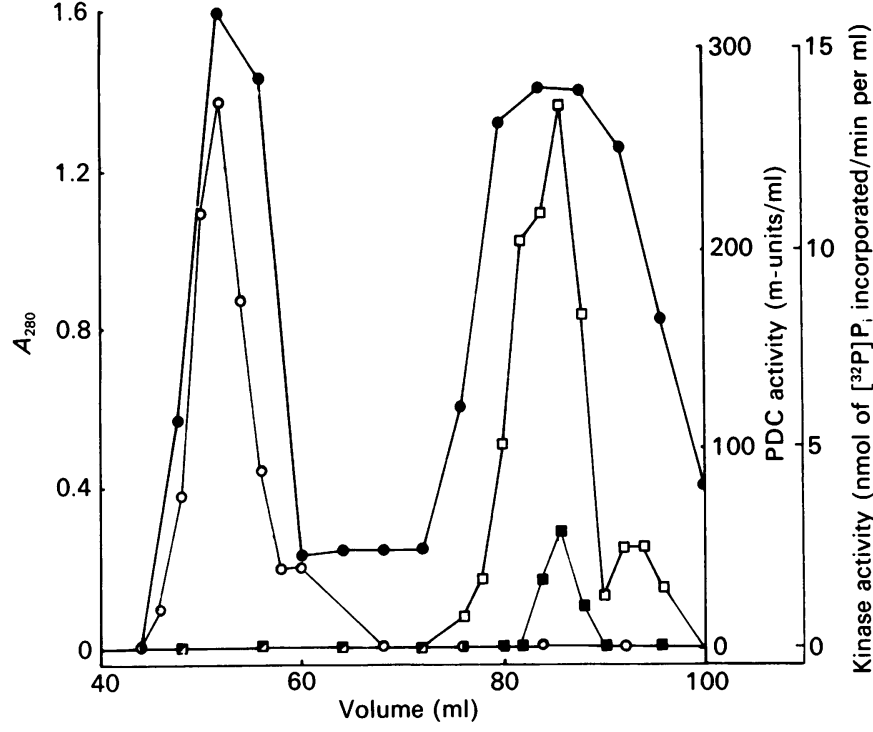

Fig. 1. Gel-filtration chromatography of rat liver mitochondrial extracts

Mitochondrial extract ( $2 \mathrm{ml}$; approx. $20 \mathrm{mg}$ of protein $/ \mathrm{ml}$ ) was subjected to gel-filtration chromatography on preparative-grade Superose $6(2 \mathrm{~cm} \times 50 \mathrm{~cm}$ column $)$, equilibrated in $50 \mathrm{mM}-\mathrm{K}_{2} \mathrm{HPO}_{4} /$ $\mathrm{KH}_{2} \mathrm{PO}_{4}$ buffer, pH 7.0, containing $10 \mathrm{~mm}$-EGTA, 1 mM-phenylmethanesulphonyl fluoride, $1 \mathrm{~mm}$-benzamidine, $0.3 \mathrm{~mm}$-tosyl-lysylchloromethane, 2 mM-dithiothreitol and $0.01 \%(w / v)$ Triton X-100. The flow rate was $1 \mathrm{ml} / \mathrm{min}$. Protein concentration was monitored by the $A_{280}(O)$, and PDC $(O)$ and $\operatorname{KAP}(\square, \square)$ activities were measured as described in the Experimental section: $\square$, KAP activity in an extract from a fed rat; $\square$, KAP activity in extract from a rat starved for $48 \mathrm{~h}$.

The column ( $1 \mathrm{ml}$ bed volume) was equilibrated in buffer $\mathbf{B}$, and protein was eluted from it by buffer B containing $100 \mathrm{mM}-\mathrm{NaCl}$. With some preparations, gel filtration was carried out on a Superose 12 analytical column equilibrated and run in buffer B containing $0.1 \%$ Triton X-100 and $100 \mathrm{~mm}-\mathrm{NaCl}$.

\section{Synthesis of phosphorylation-site peptide}

A peptide (YHGHSMSDPGVSYRKK) based on the sequence surrounding phosphorylation sites 1 and 2 on mammalian PDC E1 $\alpha$-subunit [14-16] was synthesized by Fmoc methodology on an Applied Biosystems 431A peptide synthesizer and purified by reverse-phase h.p.l.c. The lysine residues at the $C$-terminus were to ensure binding to phosphocellulose during phosphorylation assays.

\section{Assay of enzyme activities}

PDC was routinely assayed spectrophotometrically by moni-

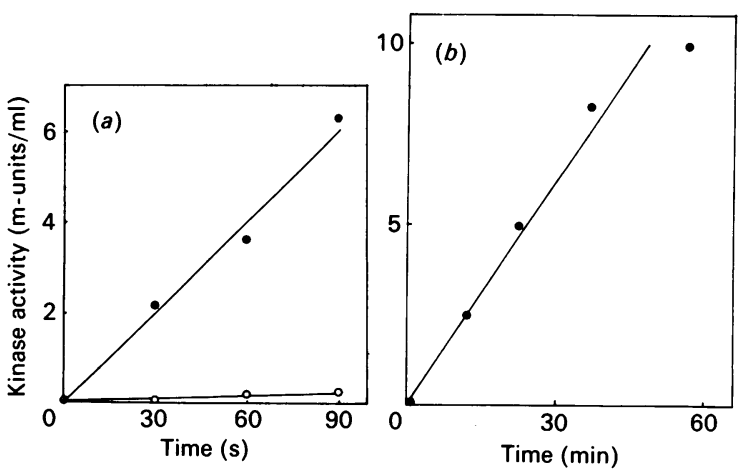

Fig. 2. Kinase activity in purified KAP preparation

Highly purified KAP $(0.9 \mu \mathrm{g}$ in $a, 0.25 \mu \mathrm{g}$ in $b)$ was added to a reaction mixture containing $50 \mathrm{~mm}$-imidazole $/ \mathrm{HCl}, \mathrm{pH} 7.2,20 \mathrm{~mm}$ $\mathrm{MgCl}_{2}, 0.2 \mathrm{mM}-\left[\gamma-{ }^{32} \mathrm{P}\right] \mathrm{ATP}$ (400000 c.p.m./nmol) and $1 \mathrm{mg}$ of PDC $\mathrm{El} / \mathrm{ml}(a)$ or $2 \mathrm{mM}$ synthetic peptide $(b):$, phosphorylation in the presence of KAP; O, phosphorylation in the absence of KAP. No detectable phosphorylation of peptide occurred in the absence of KAP. Assays were carried out as described in the Experimental section.

toring the production of NADH at $340 \mathrm{~nm}$ [17]. PDC activity in mitochondrial extracts was assayed by coupling to arylamine acetyltransferase [18], adapted to use on a Cobas Bioanalyser [19], to give minimal interference from other mitochondrial enzymes.

The activity of kinase intrinsic to the PDC complex was measured at $30^{\circ} \mathrm{C}$ either by the rate of loss of PDC activity with time in an incubation mixture containing $1 \mathrm{mg}$ of $\mathrm{PDC} / \mathrm{ml}$, $50 \mathrm{~mm}$-imidazole/ $\mathrm{HCl}, \mathrm{pH} \mathrm{7.2,2} \mathrm{mM}-\mathrm{MgCl}_{2}$ and $2 \mathrm{mM}-\mathrm{ATP}$, or by measurement of the incorporation of $\left[{ }^{32} \mathrm{P}\right] \mathrm{P}_{\mathrm{i}}$ into the complex [14]. The activity of free PDC kinase was routinely assayed as above as incorporation of $\left[{ }^{32} \mathrm{P}\right] \mathrm{P}_{1}$ from $\left[\gamma^{32} \mathrm{P}\right] \mathrm{ATP}$ into E1 $(1 \mathrm{mg} / \mathrm{ml})$ [14] or into synthetic peptide $(2 \mathrm{mM})$ [20]; 1 unit of PDC kinase activity catalyses the incorporation of $1 \mathrm{nmol}$ of phosphate from ATP/min.

The activity of KAP was assayed by its ability to increase the incorporation, by endogenous $\mathrm{PDC}$ kinase, of $\left[{ }^{32} \mathrm{P}\right] \mathrm{P}_{\mathrm{i}}$ into purified bovine heart PDC. KAP activity is expressed as the increase in the units of activity of endogenous PDC kinase.

\section{RESULTS}

When extracts of liver mitochondria of $48 \mathrm{~h}$-starved rats were subjected to gel-filtration chromatography on Superose 6, a peak of activity was detected which was devoid of PDC activity, but which stimulated the endogenous kinase activity in purified bovine heart PDC (Fig. 1). This KAP activity was approx. 3-fold

Table 1. Purification of KAP from rat liver

High-speed supernatant was prepared from the liver mitochondria of ten $48 \mathrm{~h}$-starved rats. KAP activity was measured as the increase in endogenous kinase activity in bovine heart PDC, as described in the Experimental section, and protein was determined by the method of Bradford [21].

\begin{tabular}{lcccc}
\hline Fraction & $\begin{array}{c}\text { KAP activity } \\
\text { (units) }\end{array}$ & $\begin{array}{c}\text { Protein } \\
\text { (mg) }\end{array}$ & $\begin{array}{c}\text { Specific activity } \\
\text { (units/mg) }\end{array}$ & $\begin{array}{c}\text { Purification } \\
\text { (fold) }\end{array}$ \\
\hline 150000 g supernatant & 139 & 371 & 0.374 & - \\
DE52 DEAE-cellulose & 91 & 76 & 1.20 & 3.2 \\
Orange A & 44.7 & 3.25 & 13.8 & 36.9 \\
Propac & 43.2 & 0.175 & 246.9 & 660 \\
ATP-agarose & 42.0 & 0.05 & 840.0 & 2246
\end{tabular}




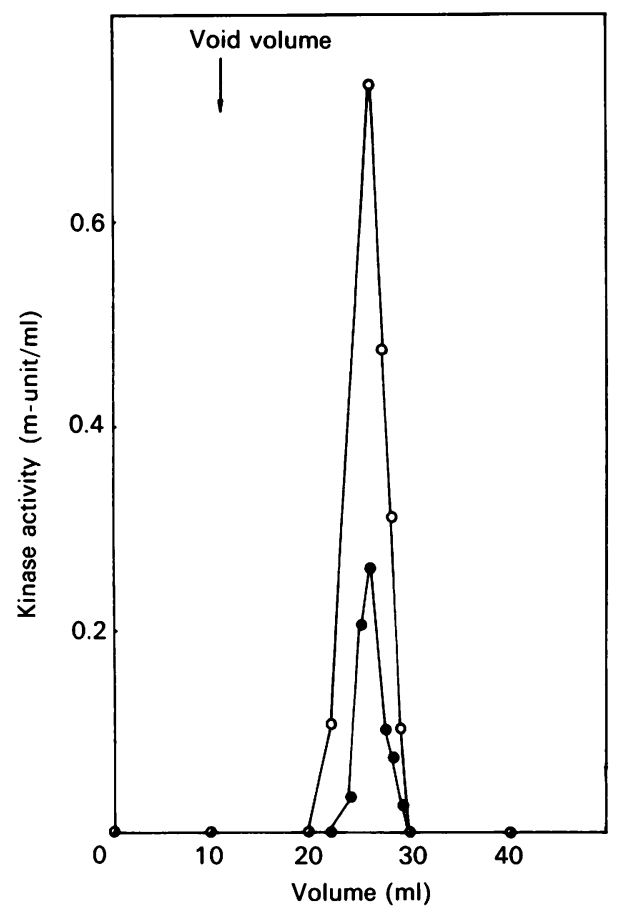

Fig. 3. Gel-filtration chromatography of KAP and PDC kinase

Highly purified preparations of KAP $(O)$ and PDC kinase $(O)$ (each $0.5 \mathrm{ml}$ ) were subjected to chromatography on analytical Superose 12, equilibrated in $50 \mathrm{~mm}$-imidazole $/ \mathrm{HCl}(\mathrm{pH} 7.2) / 50 \mathrm{~mm}$ $\mathrm{NaCl} / 1 \mathrm{~mm}$-dithiothreitol/0.01\% Triton X-100. The flow rate was $0.5 \mathrm{ml} / \mathrm{min}$. Activities were measured as described in the Experimental section.

higher in mitochondrial extracts from starved animals than from fed animals. A similar activity was detected in $150000 \mathrm{~g}$ supernatants (devoid of detectable PDC activity) prepared from liver mitochondrial extracts; again, this activity was approx. 3-fold higher in supernatants from starved rats than from fed rats. These findings are broadly in line with previous findings from another laboratory [12], and confirm the presence of a protein factor (KAP) which increases the activity of PDC kinase.

KAP was then purified extensively by successive steps, utilizing ion-exchange chromatography on DE52 DEAE-cellulose and Propac and affinity chromatography on Matrex gel Orange A and ATP-agarose. Approx. 2250-fold purification was achieved from mitochondrial high-speed supernatants, with a yield of $30 \%$ (Table 1).

A possibility that has been considered previously $[1,11]$ is that
KAP is not a distinct protein, but is PDC kinase itself, and that the apparent stimulation of endogenous kinase in PDC by KAP is due to the additional kinase in the KAP preparation. To investigate this possibility, the highly purified preparations of KAP were assayed for kinase activity, by using preparations of E1 which are essentially devoid of endogenous kinase as substrate (Fig. 2a). Significant kinase activity was observed, which was directly proportional to the volume of KAP added. To eliminate the possibility that KAP was dramatically activating a trace of kinase in the El preparation, KAP was also assayed for its ability to phosphorylate a synthetic peptide corresponding to the major phosphorylation site on PDC. It has been shown previously that peptides serve as specific substrates for the PDC kinase [22,23]. Again, significant phosphorylation of the synthetic peptide was achieved by the highly purified KAP preparation (Fig. 2b), showing unequivocally that it contains PDC kinase.

During the purification procedures, the ratio of KAP activity (i.e. stimulation of endogenous kinase in PDC) to kinase activity (against synthetic peptide) was monitored at each stage. A key finding was that this ratio was maintained at a relatively constant value (approx. 16:1) at each stage of the purification procedure (results not shown). Furthermore, KAP and kinase activities were co-eluted during the different chromatography steps. The profile of both activities on Superose 12 is shown in Fig. 3.

Further evidence that KAP is indeed PDC kinase is its ability to cause phosphorylation of PDC in a preparation of complex in which most of the endogenous kinase had been inactivated by treatment with $N$-ethylmaleimide (NEM). Whereas the KAP fraction caused a $45 \%$ increase in kinase activity in an untreated sample of PDC, it caused a $120 \%$ increase in the rate of phosphorylation in the NEM-treated complex (Table 2). However, the increment in observed kinase activity in both cases was approximately equal. Thus the increase in kinase activity after addition of KAP was unrelated to the amount of kinase endogenous in the PDC substrate, arguing against KAP acting by activating endogenous PDC kinase.

\section{DISCUSSION}

We report here several lines of evidence that the observed activity of the putative KAP can be explained by KAP being identical with PDC kinase. Perhaps the strongest evidence is that, after 2250-fold purification of KAP from high-speed supernatants prepared from mitochondrial extracts, the preparation of KAP is capable of phosphorylating a synthetic peptide containing phosphorylation sites 1 and 2 from PDC. This establishes unequivocally that this highly purified preparation contains PDC kinase activity. Although it could be argued that

\section{Table 2. Effect of KAP on NEM-treated PDC}

PDC $(1.75 \mathrm{mg} / \mathrm{ml})$ in $50 \mathrm{~mm}-\mathrm{K}_{2} \mathrm{HPO}_{4} / \mathrm{KH}_{2} \mathrm{PO}_{4}$ buffer, $\mathrm{pH} 7.0$, containing $1 \mathrm{~mm}-\mathrm{MgCl}_{2}, 1 \mathrm{~mm}-\mathrm{NaF}$ and $0.1 \mathrm{mM}-\mathrm{EDTA}$ was treated with $100 \mu \mathrm{M}-$ NEM for $15 \mathrm{~min}$ at $30^{\circ} \mathrm{C}$, followed by addition of $120 \mu \mathrm{M}$-dithiothreitol. A control sample was incubated in the absence of NEM. PDC was measured spectrophotometrically, and endogenous PDC kinase was measured as incorporation of $\left[{ }^{32} \mathrm{P}\right] \mathrm{P}_{1}$. To $5 \mu 1$ of PDC (control or NEMtreated) was then added $1 \mu \mathrm{l}$ of KAP preparation, and kinase activity was then re-assayed.

\begin{tabular}{lcccc}
\hline $\begin{array}{l}\text { PDC } \\
\text { sample }\end{array}$ & $\begin{array}{c}\text { PDC activity } \\
\text { (units/mg) }\end{array}$ & $\begin{array}{c}\text { Kinase activity } \\
\text { (m-units/mg) }\end{array}$ & $\begin{array}{c}\text { Increase in kinase } \\
\text { activity } \\
\text { (m-units/mg) }\end{array}$ & $\begin{array}{c}\text { Stimulation of } \\
\text { kinase } \\
(\%)\end{array}$ \\
\hline $\begin{array}{l}\text { Control } \\
\text { Control+KAP }\end{array}$ & 16.0 & 40.5 & & 46 \\
NEM-treated & 13.3 & 59.1 & 18.6 & 120 \\
NEM-treated +KAP & & 16.8 & 20.1 &
\end{tabular}


this preparation contains both KAP and PDC kinase, the simplest explanation of this finding is that KAP is indeed PDC kinase, a conclusion supported by the finding that the ratio of KAP activity to kinase activity remains constant during the purification procedure. This conclusion is also supported by the ability of the KAP fraction to phosphorylate homogeneous E1 which is devoid of detectable kinase activity. Furthermore, the ratio of the activity against E1 in PDC to the activity against synthetic peptide (approx. 16:1) is in excellent agreement with the corresponding value determined previously for PDC kinase [23].

The behaviour of KAP during purification is also consistent with it being identical with PDC kinase. We have found (B. S. Jones \& S. J. Yeaman, unpublished work) that the PDC kinase associated with the E1 component can be further purified by chromatography on Mono $\mathrm{Q}$ and Orange $\mathrm{A}$. Its behaviour on both these matrices is identical with that of KAP. Estimation of the $M_{\mathrm{r}}$ of PDC kinase and KAP on a calibrated Superose 12 gelfiltration column gave a value of approx. 95000 for both proteins (results not shown). Furthermore, analysis of the KAP preparations by SDS/PAGE and silver staining indicates the presence of the characteristic kinase doublet which can be observed at $M_{\mathrm{r}} 48000$. Although this material is not homogeneous, and some minor polypeptides can be observed, PDC kinase is a major protein in this preparation (results not shown).

The findings reported here have important implications for understanding of the underlying mechanism behind the decrease in PDC activity in starvation (and presumably in diabetes). Work with cultured hepatocytes has indicated that the levels of kinase are regulated by circulating amounts of glucagon and insulin [24]. It appears from our work that the major mechanism is increased amounts of PDC kinase within the mitochondria, presumably arising from increased synthesis of the constituent polypeptides. Thus transcription of the PDC kinase gene(s) is apparently under hormonal control, both in liver and in other tissues [9-12,25]. Some of this additional kinase becomes tightly associated with the complex and co-purifies during gel filtration [12], but some remains free and can be resolved from the complex by gel filtration (Fig. 1) or by ultracentrifugation (Table 1). It may be that, in starvation or diabetes, there is an excess of kinase molecules over the number of kinase-binding sites on PDC. In summary, we conclude that the increased PDC kinase activity in starvation is due to increased amounts of kinase protein, and does not involve a specific protein activator of the kinase.
B. S. J. holds a studentship from the Science and Engineering Research Council, U.K. We thank Dr. A. J. Garton for synthesis of the phosphorylation-site peptide, Dr. M. Argyraki for assistance with use of the Cobas centrifugal analyser, and Dr. K. G. Cook and Mr. P. Dent for their contribution during the early stages of this work.

\section{REFERENCES}

1. Yeaman, S. J. (1989) Biochem. J. 257, 625-632

2. Garland, P. B. \& Randle, P. J. (1964) Biochem. J. 91, 6C-7C

3. Wieland, O. H., Jagow-Westermann, B. \& Stukowski, B. (1969) Hoppe-Seyler's Z. Physiol. Chem. 350, 329-334

4. Linn, T. C., Pettit, F. H. \& Reed, L. J. (1969) Proc. Natl. Acad. Sci. U.S.A. 62, 234-241

5. Stepp, L. R., Pettit, F. H., Yeaman, S. J. \& Reed, L. J. (1983) J. Biol. Chem. 258, 9454-9458

6. Teague, W. M., Pettit, F. H., Wu, T.-L., Silberman, S. R. \& Reed, L. J. (1982) Biochemistry 21, 5585-5592

7. Pratt, M. L., Maher, J. F. \& Roche, T. E. (1982) Eur. J. Biochem. 125, 349-355

8. Wieland, O. H., Siess, E. A., Schulze-Wethmar, F. H., Funcke, H. J. \& Winton, B. (1971) Arch. Biochem. Biophys. 143, 593-601

9. Hutson, N. J. \& Randle, P. J. (1978) FEBS Lett. 92, 73-76

10. Kerbey, A. L. \& Randle, P. J. (1981) FEBS Lett. 127, 188-192

11. Kerbey, A. L. \& Randle, A. L. (1982) Biochem. J. 206, 103-111

12. Kerbey, A. L., Richardson, L. J. \& Randle, P. J. (1984) FEBS Lett. 176, 115-119

13. Stanley, C. J. \& Perham, R. N. (1980) Biochem. J. 191, 147-154

14. Yeaman, S. J., Hutcheson, E. T., Roche, T. E., Pettit, F. H., Brown, J. R., Reed, L. J., Watson, D. C. \& Dixon, G. H. (1978) Biochemistry 17, 2364-2370

15. Sugden, P. H., Kerbey, A. L., Randle, P. J., Waller, C. A. \& Reid, K. B. M. (1979) Biochem. J. 181, 419-426

16. Reed, L. J. \& Yeaman, S. J. (1987) Enzymes 3rd Ed. 18, 77-95

17. Linn, T. C., Pelley, J. W., Pettit, F. H., Hucho, F., Randall, D. D. \& Reed, L. J. (1972) Arch. Biochem. Biophys. 148, 327-342

18. Coore, H. G., Denton, R. M., Martin, B. R. \& Randle, P. J. (1971) Biochem. J. 143, 625-641

19. Argyraki, M. (1989) Ph.D. Thesis, University of Newcastle upon Tyne

20. Roskoski, R. (1983) Methods Enzymol. 99, 3-6

21. Bradford, M. M. (1976) Anal. Biochem. 72, 248-254

22. Davis, P. F., Pettit, F. H. \& Reed, L. J. (1977) Biochem. Biophys. Res. Commun. 75, 541-549

23. Mullinax, T. R., Stepp, L. R., Brown, J. R. \& Reed, L. J. (1985) Arch. Biochem. Biophys. 243, 655-659

24. Marchington, D. R., Kerbey, A. L., Giardina, M. G., Jones, A. E. \& Randle, P. J. (1989) Biochem. J. 257, 487-491

25. Fuller, S. J. \& Randle, P. J. (1984) Biochem. J. 219, 635-646

Received 29 January 1991/27 February 1991; accepted 28 February 1991 